\title{
Acute presentations of HIV are still missed in low prevalence areas
}

\author{
L Ratcliffe, ${ }^{1}$ S Thomas, ${ }^{1} \mathrm{~N} J$ Beeching, ${ }^{1,2}$ P A Phillips-Howard, ${ }^{3}$ M Taegtmeyer ${ }^{2}$
}

${ }^{1}$ Tropical and Infectious Disease Unit, Royal Liverpool University Hospital, Liverpool, UK Liverpool School of Tropical Medicine, Pembroke Place, Liverpool, UK

${ }^{3}$ Centre for Public Health, Liverpool John Moores University, Liverpool, UK

\section{Correspondence to} Dr Miriam Taegtmeyer, Liverpool School of Tropical Medicine, Pembroke Place, Liverpool L3 50A, UK: m.taegtmeyer@liverpool.ac.uk

Received 5 September 2010 Accepted 5 December 2010 Published Online First 21 January 2011

\section{ABSTRACT}

Objectives To evaluate missed opportunities and delays in the diagnosis of HIV in a low prevalence setting over a 24 year period.

Methods Patients with acute presentations of HIV were included in a retrospective note based review. Data were compared from acute presentations in 1985-2001 (88/ 241 new patients) with 2005-2007 (99/136 new patients). The number of recorded clinical and laboratory clues to infection and subsequent time delays to diagnosis of HIV were evaluated.

Results The findings reflect the shifting demographics of HIV in the UK over the past two decades, exemplified by an eightfold increase in tuberculosis at presentation. Despite recording clinical stigmata of HIV (clues) in the notes, the number of missed clues increased, and many clinicians failed to request HIV testing. The median delay between presentation and diagnosis reduced from 5 to 1 day $(p<0.001)$, and mortality dropped from $14 \%$ to $4 \%$ among patients presenting with acute symptoms. However, there was still a delay of more than 30 days before diagnosis for almost one in five patients.

Conclusions Despite some improvement and better awareness, there are still significant delays before hospital doctors consider the diagnosis of HIV for patients in low prevalence areas, even among some patient groups with high risk. Hospitals should consider moving to opt-out routine HIV testing of all medical admissions.

\section{INTRODUCTION}

An estimated 83000 people infected with HIV were reported in the UK in 2008, of whom the highest proportion live in London. HIV prevalence in North West England is low, with an average of 0.79 per 1000 persons reported infected. ${ }^{1}$ Among adults aged over 15 years who had a new diagnosis of HIV made in 2008, 32\% had a CD4 cell count $<200 \times 10^{6} / 1$ within 3 months of diagnosis. ${ }^{1}$ Patients who present late in the course of HIV disease and with low CD4 cell counts (usually $<200 \times 10^{6} / 1$ ) have higher mortality, ${ }^{2-4}$ prolonged hospital stays, and increased hospital related costs. ${ }^{5}$ These acute presentations to healthcare professionals may not be recognised by the non-specialist, prompting the Department of Health in the UK to encourage HIV testing in all settings, ${ }^{6}$ supported by new guidance on HIV testing issued by national specialist societies and patient groups in 2008 . $^{7}$

Current guidance recommends that HIV tests be offered to all persons living in areas of the UK where prevalence exceeds 2 per 1000 and that targeted testing, based on symptoms, should be conducted elsewhere. ${ }^{6}$ General physicians may be confronted with patients who present with acute disease either from seroconversion illnesses or from advanced HIV disease. While seroconversion illnesses may be diagnostically challenging, advanced HIV generally results in a number of obvious clues or 'stigmata' of immunosuppression and tables of suggestive conditions are available in HIV guidance for non-specialists. ${ }^{8}$

Missed opportunities for the diagnosis of HIV have been described elsewhere, particularly in low prevalence areas $^{9}$ and when patients present with HIV seroconversion illnesses. ${ }^{10}{ }^{11}$ In this paper we report on a study conducted in the Liverpool Tropical and Infectious Disease Unit (TIDU) (box 1), a tertiary referral unit in North West England, to identify the impact of enhanced training on the timely diagnosis of HIV among nonspecialist, general medical healthcare professionals. Using patient data from a 24 year period, we set out to assess the number of diagnostic clues that were recorded and missed at the first HIV related illness presentation to general physicians, to document delays to diagnosis of HIV and to identify factors associated with delay. We compared two time periods to see if the number of missed clues and delays in diagnosis had improved in recent years.

\section{METHODS}

\section{Data collection}

A retrospective case notes based review was performed of all HIV related presentations in Merseyside that were referred to the TIDU in Liverpool. Two cohorts of patients were evaluated and the results from the cohorts were compared. Period 1 included patients found to be HIV positive and who were referred to the TIDU, as an inpatient or outpatient, between 1 January 1983 and 31 December 2001 (figure 1). The data for this period were collected in 2002. In period 2 we reviewed case notes from a similar sized cohort of HIV patients presenting to the TIDU between January 2005 and December 2007. The cohort again consisted of newly diagnosed HIV patients and the data for this group were collected retrospectively in 2009. Patients referred solely to the clinics of the Liverpool Sexual Health Centre were excluded from either cohort. A pretested proforma was used to gather baseline data about patients on their sex, sexuality, age at HIV diagnosis, country of origin, previous HIV testing, experience of foreign travel, and intravenous drug use, together with clinical and laboratory features of infection and details of the time between presentation and diagnosis of HIV. The same proforma was used for both cohorts. 
Box 1 Details of Tropical and Infectious Disease Unit, Liverpool

The Tropical and Infectious Disease Unit (TIDU) in Liverpool provides outpatient and inpatient care for people with HIV, and was previously located at the University Hospital Aintree, where same day testing for HIV was available from 1995 onwards. In December 2001 the TIDU moved to its current site, where comprehensive HIV services are provided jointly with the Liverpool Sexual Health Centre (Department of Genitourinary Medicine), which sees the majority of people with asymptomatic new presentations of HIV in the Mersey region.

\section{Initial training}

The initial findings from the cohort of patients in period 1, related to delays in diagnosis, were used to train medical students, accident and emergency (A\&E) trainees, general practitioners, and hospital staff from 2001 to 2006 . This was done through organised teaching sessions with these groups of healthcare professionals, as it was felt that they were the people most likely to see these patients initially: educating them with regard to HIV testing may have allowed the diagnosis to be made earlier and thereby reduce the morbidity and mortality associated with delayed diagnosis. The teaching was carried out using case studies of acute presentations of HIV, and a 'targeted' approach to testing was encouraged, based on indicator findings in the medical history and examination. Further publicity about the need for HIV testing was emphasised at other postgraduate events in the hospital-for example, at 'grand rounds' and in educational displays and events for the public and staff on HIV days, etc. The second cohort was then evaluated and compared to the cohort from period 1, to assess if continued education among healthcare workers led to an improvement in the time to diagnosis of HIV, with reduced delays to testing among these patients.

\section{Definitions used in data collection}

We defined acute presentations as being patients with an unknown HIV status when presenting to hospital with an HIV related illness that required hospital admission or an urgent consultant outpatient opinion. A spectrum of HIV related illness
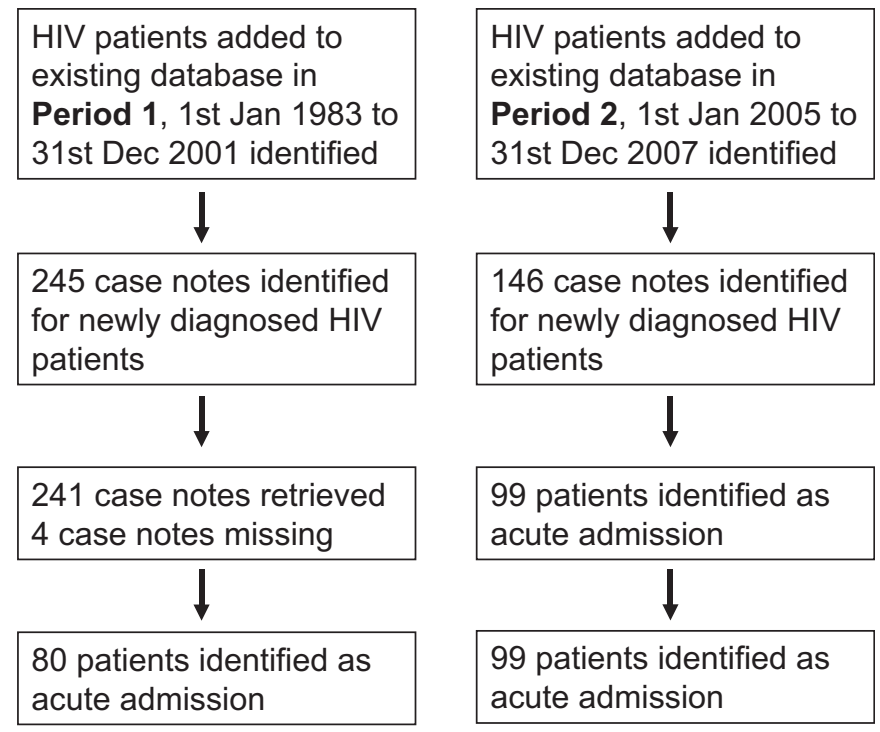

Figure 1 Patient identification in the two cohorts. from seroconversion to advanced HIV disease was included. 'Clues' to HIV disease were defined as: known epidemiological and behavioural risk factors, relevant past medical history, clinical stigmata of HIV disease on examination, and baseline investigation consistent with underlying HIV infection. The number of clues documented in the initial clerking was recorded ('recorded clues') and compared to those identified by a specialist during the same admission, the difference being defined as 'missed clues'.

\section{Data analysis}

The study was registered with the hospital clinical information audit committee and all personal data were stored and analysed in accordance with national guidelines. ${ }^{12}$ Epi info 2000 version 3.5.1 was used to perform statistical analysis using the Mann-Whitney U test and Fisher's exact test. These were used to calculate and compare delays to diagnosis of HIV, frequency of risk factors, mean number of clues and missed clues, and median delays to diagnosis within the two cohorts. Interquartile ranges are given to illustrate the range in diagnostic delays.

\section{RESULTS}

\section{Demographics}

During period 1, out of a possible 245 patient case notes, 241 $(98.4 \%)$ were retrieved. Of these, $209(87 \%)$ were male and 207 (86\%) were from the UK. In the second period, 136/146 (93.2\%) case notes of patients were retrieved, $82(60 \%)$ of whom were male and $59(43 \%)$ were from sub-Saharan Africa. There was, in tandem, a significant $(p<0.001)$ reduction in cases in men who have sex with men. Using the previous definitions, we identified 80/241 (33.2\%) presentations as acute in period 1 and 99/136 $(72.8 \%)$ in period 2 (figure 1). Baseline demographics are summarised in table 1 . Immediate hospital mortality was $11 / 80$ $(14 \%)$ admissions in the first period and 4/99 (4\%) in the second period $(p=0.04)$.

Table 1 Demographic features of two cohorts of patients presenting acutely with HIV in 1983-2001 and 2005-2007

\begin{tabular}{lcrlrc}
\hline & $\begin{array}{l}\mathbf{1 9 8 3 - 2 0 0 1} \\
\mathbf{n = 8 0}\end{array}$ & $\mathbf{( \% )}$ & $\begin{array}{l}\mathbf{2 0 0 5 - 2 0 0 7} \\
\mathbf{n = 9 9}\end{array}$ & $\mathbf{( \% )}$ & $\mathbf{p ~ V a l u e *}^{*}$ \\
\hline Characteristics & & & & & \\
Female & 10 & $\mathbf{1 2 . 5}$ & 38 & $\mathbf{3 8 . 4}$ & $<0.001$ \\
Age $>$ 40 & 23 & $\mathbf{2 8 . 8}$ & 32 & $\mathbf{3 2 . 3}$ & 0.629 \\
Origin & & & & & \\
$\quad$ UK & 65 & $\mathbf{8 1 . 2}$ & 47 & $\mathbf{4 7 . 5}$ & $<0.001$ \\
SSA & 11 & $\mathbf{1 3 . 8}$ & 43 & $\mathbf{4 3 . 4}$ & $<0.001$ \\
Other & 4 & $\mathbf{5 . 0}$ & 9 & $\mathbf{9 . 1}$ & 0.39 \\
Risks & & & & & \\
MSM & 42 & $\mathbf{5 2 . 5}$ & 18 & $\mathbf{1 8 . 2}$ & $<0.001$ \\
IVDU & 7 & $\mathbf{8 . 8}$ & 5 & $\mathbf{5 . 1}$ & 0.377 \\
Travel & 26 & $\mathbf{3 2 . 5}$ & 56 & $\mathbf{5 6 . 6}$ & 0.0015 \\
Expatriate & 14 & $\mathbf{1 7 . 5}$ & 0 & $\mathbf{0}$ & $<0.001$ \\
CSW & 2 & $\mathbf{2 . 5}$ & 0 & $\mathbf{0}$ & 0.198 \\
Where acquired & & & & & \\
UK & 45 & $\mathbf{5 6 . 3}$ & 43 & $\mathbf{4 3 . 4}$ & 0.0995 \\
SSA & 20 & $\mathbf{2 5 . 0}$ & 46 & $\mathbf{4 6 . 5}$ & 0.003 \\
N America & 9 & $\mathbf{1 1 . 2}$ & 2 & $\mathbf{2 . 0}$ & 0.013 \\
Elsewhere & 6 & $\mathbf{7 . 5}$ & 8 & $\mathbf{8 . 1}$ & 1 \\
Presentation stage & & & & & \\
CD4 $<$ 200 & 50 & $\mathbf{6 2 . 5}$ & 67 & $\mathbf{6 7 . 7}$ & 0.528 \\
CD4 $>$ 200 & 27 & $\mathbf{3 3 . 8}$ & 29 & $\mathbf{2 9 . 3}$ & 0.627 \\
CD4 not known & 3 & $\mathbf{3 . 7}$ & 3 & $\mathbf{3 . 0}$ & 1 \\
\hline
\end{tabular}

*Fisher's exact test.

CSW, commercial sex worker; IVDU, intravenous drug user; MSM, men who have sex with men; SSA, sub-Saharan Africa. 


\section{Clinical findings}

The clinical stigmata of HIV disease at the time of acute presentation revealed the importance of a history of previous sexually transmitted infection (STI), dry skin, pneumonia, and chronic diarrhoea as well as the social and travel history (table 2). Lymphadenopathy, respiratory distress, oral candidiasis, and dermatitis were the most common clinical signs in both periods. The most often recorded haematological abnormalities were anaemia and lymphopenia, together with thrombocytopenia and hyperglobulinaemia. The mean (SD) recorded clinical clues were 5.8 (2.54) and 4.5 (2.16) in periods 1 and 2, respectively $(p<0.01)$; the mean number of missed clues increased significantly between the two cohorts, rising from 1.8 (2.01) to 4.0 (2.51) ( $p<0.01)$.

\section{Diagnosis of HIV associated diseases and opportunistic infections}

In both periods, approximately $60 \%$ of people who presented acutely had opportunistic infections (OI), indicating advanced HIV disease, and had CD4 white cell counts <20010\%/1 (data not shown). The most common AIDS defining diagnoses were Pneumocystis jirovecii pneumonia (PCP) in 21 (28.8\%) and AIDS related malignancies in $5(6.8 \%)$ in period 1 , and PCP in 22 $(23.2 \%)$ and tuberculosis (TB) in $24(23.2 \%)$ in period 2 . The proportion of cases co-infected with TB rose eightfold from $2.7 \%$ to $23.2 \%$ between the two cohorts. A further $30 \%$ presented with HIV related conditions such as herpes zoster, pneumococcal pneumonia, and oral candidiasis, and $16.4 \%$ and $8.1 \%$ of

Table 2 Recorded clues (medical history, clinical examination and blood results) in descending order of frequency

\begin{tabular}{|c|c|c|c|c|c|}
\hline & $\begin{array}{l}1983-2001 \\
N=77\end{array}$ & $\%$ & $\begin{array}{l}2005-2007 \\
N=99\end{array}$ & $\%$ & p Value \\
\hline \multicolumn{6}{|l|}{ Past medical history } \\
\hline Travel history & 32 & 41.6 & 40 & 40.4 & 0.879 \\
\hline MSM & 28 & 36.4 & 12 & 12.1 & $<0.001$ \\
\hline STI & 9 & 11.7 & 7 & 7.1 & 0.305 \\
\hline Dry skin & 8 & 10.4 & 23 & 23.2 & 0.03 \\
\hline IVDU & 7 & 9.1 & 5 & 5.1 & 0.37 \\
\hline HBV infection & 6 & 7.8 & 0 & 0 & 0.006 \\
\hline Pneumococcal pneumonia & 5 & 6.5 & 18 & 18.2 & 0.025 \\
\hline Oral candidiasis & 5 & 6.5 & 16 & 16.2 & 0.06 \\
\hline Chronic diarrhoea & 7 & 9.1 & 3 & 3.0 & 0.107 \\
\hline Shingles & 3 & 3.9 & 4 & 4.0 & 1 \\
\hline TB infection & 2 & 2.6 & 3 & 3.0 & 1 \\
\hline Blood transfusion & 2 & 2.6 & 3 & 3.0 & 1 \\
\hline Refugee & 1 & 1.3 & 5 & 5.1 & 0.23 \\
\hline \multicolumn{6}{|l|}{ Clinical examination } \\
\hline Lymphadenopathy & 19 & 24.7 & 35 & 35.4 & 0.141 \\
\hline Unexplained hypoxia & 19 & 24.7 & 37 & 37.4 & 0.08 \\
\hline Oral candidiasis & 17 & 22.1 & 22 & 22.2 & 1 \\
\hline Other (cachexia, etc) & 16 & 20.8 & 0 & 0 & $<0.001$ \\
\hline Neurological deficit & 14 & 18.2 & 15 & 15.1 & 0.683 \\
\hline Dermatitis & 9 & 11.7 & 29 & 29.3 & 0.005 \\
\hline Maculopapular rash & 7 & 9.1 & 10 & 10.1 & 1 \\
\hline Shingles scar & 2 & 2.6 & 8 & 8.1 & 0.108 \\
\hline KS lesion & 2 & 2.6 & 7 & 7.1 & 0.302 \\
\hline \multicolumn{6}{|l|}{ Blood results } \\
\hline Anaemia & 38 & 49.3 & 60 & 60.6 & 0.168 \\
\hline Lymphopenia & 28 & 36.4 & 30 & 30.3 & 0.422 \\
\hline Increased globulins & 28 & 36.4 & 57 & 57.6 & 0.006 \\
\hline Thrombocytopenia & 16 & 20.8 & 10 & 10.1 & 0.06 \\
\hline
\end{tabular}

*Fisher's exact test.

HBV, hepatitis B virus; IVDU, intravenous drug user; KS, Kaposi's sarcoma; MSM, men who have sex with men; STI sexually transmitted infection; TB, tuberculosis. the cohorts, respectively, presented with acute HIV seroconversion illnesses.

\section{Delays to diagnosis}

The median delays to diagnosis of HIV (table 3) were 5 and 1 days, respectively, between the two cohorts $(p<0.001)$, but with a skewed pattern of distribution, with the greatest reduction seen in patients presenting with OI/AIDS (6 to 1 day; $\mathrm{p}<0.001)$. There was a delay of more than 30 days between presentation and diagnosis in $31 / 171$ (18.1\%) patients, with a non-significant trend for this to be more common for women $(12 / 47 ; 25.6 \%)$ than for men $(19 / 124 ; 15.3 \%)(p=0.19)$. Similar non-significant trends were seen in patients with seroconversion illness $(5 / 20 ; 25 \%)$ compared to those presenting with obvious late stage disease $(14 / 100 ; 14 \%)$.

\section{DISCUSSION}

In these cohorts of people presenting with HIV over more than two decades, there has been no decrease in the number or proportion of people presenting acutely. We documented a reduction in the average time taken to diagnose HIV in these groups as junior doctors and generalists increased their awareness through organised educational sessions, as well as national awareness programmes. However, despite overall improvement in the recognition of HIV, some long delays remained. These may have been exacerbated by a paucity of clinical documentation in the second period, as reflected in the increasing proportion of 'missed' as opposed to 'recorded' clues in the case notes (table 2). There was no significant improvement in the time delay to diagnosis in women, in those aged over 40, in those from sub-Saharan Africa, ${ }^{5}$ and those with a seroconversion illness. The latter requires a high index of suspicion and suggests further need for improvement in clinical education and training for non-specialists to recognise presentations. ${ }^{8} 10$

Table 3 Median delay in days and interquartile range (IOR) from presenting illness to HIV diagnosis in two time periods

\begin{tabular}{|c|c|c|c|c|c|}
\hline & $\begin{array}{l}1983-2001 \\
N=72\end{array}$ & IOR & $\begin{array}{l}2005-2007 \\
N=99\end{array}$ & IOR & p Value* \\
\hline Total & 5 & $2-27.5$ & 1 & $0-9$ & $<0.001$ \\
\hline \multicolumn{6}{|l|}{ Characteristics } \\
\hline Female & 7 & $4-174$ & 2.5 & $0-15$ & 0.05 \\
\hline Male & 5 & $2-18$ & 1 & $0-7$ & $<0.001$ \\
\hline Age $>40$ years & 5 & $1-15.5$ & 2.5 & $0-9$ & 0.08 \\
\hline Age $\leq 40$ years & 5.5 & $2.5-33.5$ & 1 & $0-7$ & $<0.001$ \\
\hline \multicolumn{6}{|l|}{ Origin } \\
\hline UK & 5.0 & $2-34$ & 0 & $0-9$ & $<0.001$ \\
\hline SSA & 6.5 & $1-9$ & 2 & $0-9$ & 0.29 \\
\hline Other & 5.5 & $3.5-41.5$ & 1 & $0-5$ & 0.12 \\
\hline \multicolumn{6}{|l|}{ Risks } \\
\hline MSM & 6.0 & $1.5-29.5$ & 0 & $0-11$ & 0.005 \\
\hline IVDU & 4.0 & $3-5$ & 6 & $5-31$ & 0.16 \\
\hline Travel & 5.0 & $1-77$ & 1.5 & $0-7$ & 0.04 \\
\hline \multicolumn{6}{|l|}{ CD4 } \\
\hline CD4 $<200$ & $5 \mathrm{~N}=46$ & $2-13$ & $2 \mathrm{~N}=67$ & $0-9$ & 0.004 \\
\hline $\operatorname{CD} 4>200$ & $5 \mathrm{~N}=25$ & $1-34$ & $0 \mathrm{~N}=29$ & $0-12$ & 0.02 \\
\hline \multicolumn{6}{|l|}{ Presenting illness } \\
\hline Ol/AIDS & 6 & $2-13$ & 1 & $0-7$ & $<0.001$ \\
\hline Non AIDS HIV related & 5 & $4-37$ & 2 & $0-13$ & 0.21 \\
\hline HIV seroconversion & 4.5 & $0.5-144.5$ & 0 & $0-6$ & 0.06 \\
\hline
\end{tabular}

*Mann-Whitney U test.

IVDU, intravenous drug user; MSM, men who have sex with men; Ol, opportunistic infection; SSA, sub-Saharan Africa. 
The Merseyside cohorts illustrate the nationwide shift in demographics of HIV infection, ${ }^{13}$ and the corresponding change in patterns of presentation, with more HIV related reactivation of TB in the later time period. ${ }^{5}{ }^{14}$ Our study did not take into account the contribution of patients with poor English skills, reported to be a contributory factor in delayed HIV diagnosis in TB patients. ${ }^{15}$ While the differences seen in social, travel, and medical history reflect these shifting demographics, the clinical signs were similar in both time periods (table 2) and provide a useful checklist for the non-specialist.

Previous studies on missed opportunities for timely and accurate diagnoses of HIV infections have shown that delays to diagnosis are common, even in late presentations, especially for heterosexual and older people who do not fit the HIV risk profile 'stereotype'. ${ }^{16}$ Some delays are patient related, and patients who do not perceive themselves to be at risk of HIV are less likely to access healthcare and are more likely to present with late stage infections. ${ }^{5}$ More complex factors lead to reluctance of some high risk groups of migrants from seeking diagnostic testing. ${ }^{17} 18$

Delays occur regardless of specialty ${ }^{19}$ and, while some patients present themselves late in the course of HIV infection, the majority have contact with medical professionals during earlier stages of the disease and, as we found, many have obvious stigmata of HIV. Similar failures to consider obvious stigmata have been reported in various clinic settings in Boston, USA, where patients made a median of five visits to outpatient and emergency room clinics and HIV was only considered in $27 \%$ of visits in which clues were identified. ${ }^{20}$ Almost one in five of our patients had symptoms for more than 30 days before diagnosis, although the median delay to diagnosis after presentation was only a few days, similar to previous $\mathrm{US}^{21}$ and UK reports. ${ }^{5}$ The non-significant but increased delay in diagnosing intravenous drug users may require further exploration.

Clinical triggers that are repeatedly missed by clinicians are lymphadenopathy, ${ }^{22}$ oral candidiasis, herpes and other oral lesions, ${ }^{23}$ and herpes zoster. ${ }^{24}$ Clues in the routine biochemical screen and blood count are commonly missed including hyperglobulinaemia, anaemia, neutropenia, lymphopenia, and thrombocytopenia. ${ }^{25}$ Acute seroconversion illness is underdiagnosed $^{10}$ and may present with a variety of syndromes including meningoencephalitis. ${ }^{26}$ The need to consider HIV in all patients with a lymphoma has been re-emphasised recently, ${ }^{27} 28$ as has the need for expanded testing in intensive care units. ${ }^{29}$

Our findings indicate an improvement in diagnostic delays in hospital inpatients in known risk groups, although there is no definite link between our attempts to provide refresher courses for generalists and the improved early detection of HIV.

Furthermore, the increased national awareness raising among some high risk groups does not appear to have had an effect on the rates of acute presentations over time, in part because of the shift in the epidemiology of HIV in recent years. Our hospital has seen some improvement in the diagnosis of HIV, but there is no room for complacency. A shift to routine opt-out testing at times of contact with medical professionals ${ }^{30} 31$ would overcome the concerns of generalists about when to offer HIV testing, and to whom, and would improve the timely diagnosis of asymptomatic and early HIV infection. However, logistic and ethical issues continue to hinder the introduction of routine testing in some emergency rooms, ${ }^{32}{ }^{33}$ and the most cost effective and non-intrusive way to overcome such obstacles needs further evaluation in low prevalence settings in the UK. This is even more pertinent in light of the recent evidence that early initiation of antiretroviral therapy is associated with better outcomes. ${ }^{34} 35$

\section{Main messages}

- There has been a major demographic shift in the UK, which has had an impact on HIV presentations to primary and secondary care.

- When patients with underlying HIV infection present to healthcare providers, there are often several clues related to the underlying infection.

- Opportunities to make the diagnosis of HIV early in the disease process are being missed, potentially leading to increased morbidity and mortality.

- Continued education among generalists may improve rates of HIV diagnosis.

- 'Opt-out' testing may be an appropriate approach to testing patients in order to reduce the delays in diagnosis.

\section{Current research questions}

- How can the recognition of clues to the diagnosis of HIV be improved in primary care?

- How can the recognition of clues to the diagnosis of HIV be improved in secondary care?

- What is the best educational programme to maintain diagnostic acumen in a setting with low prevalence of HIV?

- Is the introduction of an 'opt-out' testing approach for HIV feasible and cost effective in acute medical admission units, especially in low prevalence settings?

Findings from this study were limited by the method and type of case reporting, but this remained relatively standard between the two cohorts examined. While the two cohorts were of similar sizes, the second accumulated over a shorter time span reflecting higher incidence, which may have had an impact on (enhanced) recognition of signs. The reliance on routine documentation within medical records was a limitation, and missing data may have compromised full evaluation. Furthermore, we do not have data on previous contacts with primary care. The relative clinical significance of missed clues is not accounted for, with all being given the same weighting, when in reality some are stronger indicators of underlying HIV than others. However, there is little evidence to suggest this resulted in any systematic error favouring a particular subgroup or time period. Furthermore, contemporaneous reporting to the North West Monitoring System suggests our findings are in keeping with regional shifts in patient characteristics. ${ }^{13}$

\section{CONCLUSION}

As elsewhere in the UK, there has been a major demographic shift in HIV presentations, which in turn has had an impact on HIV diagnosis. We showed a reduction in the median delay to diagnosis, but opportunities for testing are still being missed, particularly in women, older people, and those with seroconversion illnesses. Our data suggest that a change from targeted to routine 'opt-out' testing in acute medical admissions in the UK may be appropriate in order to reduce these delays to making a diagnosis of HIV and related illnesses. This would, in turn, improve the prognosis for those diagnosed early and reduce hospital stays. 
Acknowledgements The authors would like to acknowledge Dr Fred Nye, consultant at the TIDU during the whole time period of the first review, and $\mathrm{Dr}$ Alastair Miller and Dr Mike Beadsworth who provided consultant supervision and patient care during the second time period of the review. Dr Brian Faragher of the Liverpool School of Tropical Medicine and Dr Jane Davies from TIDU reviewed and critically appraised the tables and text.

Competing interests None

Contributors NJB and MT initiated the idea; LR and ST entered and analysed the data; MT, PPH, and LR wrote the paper; NJB and ST revised and supplemented the text; NJB will act as guarantor of the paper.

Provenance and peer review Not commissioned; externally peer reviewed.

\section{REFERENCES}

1. Health Protection Agency. HIV in the United Kingdom: 2009 Report. London, 2009. http://www.hpa.org.uk/web/HPAweb\&HPAwebStandard/HPAweb_C/ 1259151891866 (accessed 5 Nov 2010).

2. Lucas SB, Curtis $\mathrm{H}$, Johnson MA. National review of deaths among HIV-infected adults. Clin Med 2008;8:250-2.

3. Sullivan AK, Curtis H, Sabin CA, et al. Newly diagnosed HIV infections: review in UK and Ireland. BMJ 2005:330:1301-2.

4. Chadborn TR, Delpech VC, Sabin CA, et al. The late diagnosis and consequent short-term mortality of HIV-infected heterosexuals (England and Wales, 2000-2004). AIDS 2006;20:2371-9.

5. Udayaraj UP, Tang A, Vaux E, et al. HIV-related admissions to a district general hospital in the UK: a single centre study. Clin Med 2009;9:333-7.

6. Department of Health. Improving the Detection and Diagnosis of HIV in Non-HIV Specialties Including Primary Care. [document on internet]. London: DoH, 2007. http://www.dh.gov.uk/prod consum dh/groups/dh digitalassets/@dh/@en/ documents/digitalasset/dh 082338. pdf (accessed $\overline{5}$ Nov 2010).

7. British HIV Association (BHIVA), British Association for Sexual Health and HIV (BASHH), British Infection Society (BIS). UK National Guidelines for HIV Testing 2008. BHIVA, 2008. http://www.bhiva.org/files/file1031097.pdf (accessed 5 Nov 2010)

8. Baggeley R. HIV for non-HIV specialists: diagnosing the undiagnosed. Medical Foundation for AIDS and Sexual Health (MedFASH). London, 2008. http://www. medfash.org.uk/publications/documents/HIV for non HIV specialists.pdf laccessed 5 Nov 2010)

9. McDonald EA, Currie MJ, Bowden FJ. Delayed diagnosis of HIV: missed opportunities and triggers for testing in the Australian Capital Territory. Sex Health 2006; $\mathbf{3}: 291-5$

10. Sudarshi D, Pao D, Murphy G, et al. Missed opportunities for diagnosing primary HIV infection. Sex Transm Infect 2008:84:14-16.

11. Weintrob AC, Giner J, Menezes $P$, et al. Infrequent diagnosis of primary human immunodeficiency virus infection: missed opportunities in acute care settings. Arch Intern Med 2003;163:2097-100.

12. Department of Health. The Caldicott Committee Report on the Review of PatientIdentifiable Information. Human Tissue Act 1997. London: Department of Health http://www.dh.gov.uk/en/Publicationsandstatistics/Publications/PublicationsPolicy AndGuidance/DH 4006467 (accessed 5 Nov 2010).

13. Downing J, Cook PA, Bellis MA. Ten years of monitoring HIV \& AIDS in the North West of England. Centre for Public Health, Liverpool John Moores University, 2007. ISBN 978-1-902051-58-0. http://www.nwpho.org.uk/10yearhiv/ (accessed 5 Nov 2010).
14. Crofts J, Gleb D, Andrews N, et al. Investigating tuberculosis trends in England Public Health 2008;122:1302-10.

15. Rodger A, Story A, Fox Z, et al. HIV prevalence and testing practices among tuberculosis cases in London: a missed opportunity for HIV diagnosis. Thorax 2010;65:63-9

16. Delpierre C, Dray-Spira R, Cuzin L, et al. Correlates of late HIV diagnosis: implications for testing policy. Int J STD AIDS 2007;18:312-17.

17. Burns FM, Johnson AM, Nazroo J, et al. Missed opportunities for earlier HIV diagnosis within primary and secondary healthcare settings in the UK. AIDS 2008:22:115-22

18. Thomas $\mathbf{F}$, Aggleton $P$, Anderson J. "If I cannot access services, then there is no reason for me to test": the impacts of health service charges on HIV testing and treatment amongst migrants in England. AIDS Care 2010;22:526-31.

19. Lee V, Foley E, Patel R. Evaluation of time for non-GU medicine physicians to diagnose HIV infection in patients presenting with HIV-related illnesses. Int J STD AIDS 2006:17:97-8.

20. Liddicoat RV, Horton NJ, Urban R, et al. Assessing missed opportunities for HIV testing in medical settings. J Gen Intern Med 2004;19:349-56.

21. Kuo AM, Haukoos JS, Witt MD, et al. Recognition of undiagnosed HIV infection: an evaluation of missed opportunities in a predominantly urban minority population. AIDS Patient Care STDS 2005;19:239-46.

22. Sam WI, Nye FJ, Beeching NJ, et al. Delayed diagnosis of HIV in patients with reactive lymphadenopathy. Hosp Med 2000:61:578-9.

23. Reznik DA. Oral manifestations of HIV disease. Top HIV Med 2005;13:143-8.

24. Hung CC, Hsiao CF, Wang JL, et al. Herpes zoster in HIV-1-infected patients in the era of highly active antiretroviral therapy: a prospective observational study. Int J STD AIDS 2005:16:673-6.

25. Sloand E. Hematologic complications of HIV infection. AIDS Rev 2005; 7:187-96.

26. Newton PJ, Newsholme W, Brink NS, et al. Acute meningocephalitis and meningitis due to primary HIV infection. BMJ 2002;325:1125-7.

27. Carbone A, Cesarman E, Spina M, et al. HIV-associated lymphomas and gammaherpesviruses. Blood 2009:113:1213-24.

28. Cave J, Edwards SG, Miller RF, et al. Should we implement 'opt-out' HIV testing for patients with lymphoma? Clin Med 2009;9:320-2.

29. Taegtmeyer M, Beeching N. Practical approaches to HIV testing in the intensive care unit. JICS 2008;9:37-41. http://journal.ics.ac.uk/pdf/0901037.pdf laccessed 5 Nov 2010).

30. Hamill M, Burgoine K, Farrell F, et al. Time to move towards opt-out testing for HIV in the UK. BMJ 2007;334:1352-4.

31. Delpierre C, Cuzin L, Lert F. Routine testing to reduce late HIV diagnosis in France. BMJ 2007;334:1354-6.

32. White DA, Warren OU, Scribner AN, et al. Missed opportunities for earlier HIV diagnosis in an emergency department despite an HIV screening program. AIDS Patient Care STD 2009;23:245-50.

33. Torres M. Rapid HIV screening in the emergency department. Emerg Med Clin North Am 2010;28:369-80.

34. Gazzard BG, Anderson J, Babiker A, et al. British HIV Association guidelines for the treatment of HIV-1-infected adults with antiretroviral therapy 2008. HIV Medicine 2008;9:563-608

35. Panel on Antiretroviral Guidelines for Adults and Adolescents. Guidelines for the Use of Antiretroviral Agents in HIV-1-Infected Adults and Adolescents. Department of Health and Human Services, 2009:1-161. http://www.aidsinfo.nih.gov/ ContentFiles/AdultandAdolescentGL.pdf. (accessed 5 Nov 2010). 


\section{Acute presentations of HIV are still missed in low prevalence areas}

L Ratcliffe, S Thomas, N J Beeching, et al.

Postgrad Med J 2011 87: 170-174 originally published online January 21,2011

doi: 10.1136/pgmj.2010.109801

Updated information and services can be found at:

http://pmj.bmj.com/content/87/1025/170.full.html

These include:

References This article cites 28 articles, 11 of which can be accessed free at: http://pmj.bmj.com/content/87/1025/170.full.htmI\#ref-list-1

Email alerting Receive free email alerts when new articles cite this article. Sign up in service the box at the top right corner of the online article.

Notes

To request permissions go to:

http://group.bmj.com/group/rights-licensing/permissions

To order reprints go to:

http://journals.bmj.com/cgi/reprintform

To subscribe to BMJ go to:

http://group.bmj.com/subscribe/ 